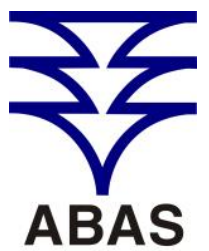

ASSOCIACAOBRASLLERADE
AGUAS SUBTERRANEAS www.abas.org

\section{O USO DE FERRAMENTAS GEOQUÍMICAS NA IDENTIFICAÇÃO DO COMPORTAMENTO DA CUNHA SALINA DO AQUÍFERO COSTEIRO DO DISTRITO DE ITAIPUAÇU, MARICÁ - RJ}

\author{
THE USE OF GECHEMICAL TOOLS TO ASSESS SALINE WEDGE BEHAVIOUR \\ IN ITAIPUACYU DISTRICT COASTAL AQUIFER, \\ MARICÁ, BRAZIL
}

Gerson Cardoso da Silva Jr ${ }^{1}$, Vinicius do Nascimento Cristo ${ }^{2}$

\begin{abstract}
Research concerning saltwater-freshwater interfaces in coastal aquifers is becoming more frequent due to the increasing number of groundwater salinization problems in coastal areas around the world. Groundwater is, so far, the only source of drinking water in the Itaipuaçu district, Maricá, in State of Rio de Janeiro, Brazil, with great social and economic importance. The resource utilization is carried out without control with little, if any, regulation on the implantation and use of groundwater, usually shallow wells. The present work aimed to study the Itaipuaçu coastal aquifer functioning through a geochemical characterization, enabling the preparation of a conceptual model as support for a subsequent mathematical modeling. As a secondary objective, an attempt was made to compare the temporal data generated by other authors in previous research in Itaipuaçu. The information collected in this study aided the interpretation of the salt wedge behavior, held for more than a decade (2000 - 2010 / 2012). The methodology included a survey of available databases, selection of compatible water points (as it involved collecting groundwater samples at intervals between samples of up to ten years), field campaigns to collect samples in a network of wells pre-existing monitoring parameters in situ measurements and chemical analyzes in a laboratory. The parameters examined in this study included the major ions (chloride, bicarbonate, sulfate, calcium, magnesium, sodium, potassium) and bromide, as well as $\mathrm{pH}$ and electrical conductivity (EC). This choice was elected to make possible the eventual application of ionic ratios, a valuable tool in identification of the origin and characteristics of aquifer salinity. Research results show that Itaipuaçu region still has no significant problems related to the migration of the salt wedge, the geochemical evidence in the saline interface. Presence of groundwater with different dominant spatial and temporal geochemical processes were observed: dissolution of salts from the marine aerosol, ion exchange, especially between calcium and sodium, evaporative processes. The results also indicate that the situation could become critical if breakup of the fragile site hydrodynamic balance occurred, such as the continuous increase in pumping due to house building boom and expansion of urban occupation and associated civil works (canals, landfills, etc.).
\end{abstract}

Keywords: Saline interface. Coastal aquifer. Hydrogeochemistry. Itaipuaçu-Maricá. Rio de Janeiro.

Resumo: Estudos realizados sobre o tema da presença e comportamento de interfaces salinas em aquíferos são cada vez mais frequentes, principalmente devido ao crescente número de problemas com a salinização da água subterrânea em áreas de grande importância social e econômica, como as áreas costeiras em todo o mundo. A água subterrânea é, até o momento, a única fonte autóctone de água potável no distrito de Itaipuaçu, sendo de grande relevância social e econômica. A utilização do recurso é realizada de forma desordenada, havendo escasso a nulo controle na implantação e utilização das captações subterrâneas, em geral de poços rasos. O presente trabalho teve como objetivo estudar o funcionamento do aquífero costeiro de Itaipuaçu através de uma caracterização geoquímica a partir da qual elaborou-se um modelo conceitual que servirá como apoio a uma modelagem matemática posterior. Como objetivo secundário, tentou-se comparar temporalmente os dados gerados por outros autores em pesquisas anteriores na área de Itaipuaçu, distrito oceânico do município de Maricá-RJ. As informações coletadas na presente pesquisa auxiliaram no monitoramento do comportamento da cunha salina, realizado durante mais de uma década (2000 - 2010/2012). A metodologia incluiu a pesquisa de bancos de dados disponíveis, seleção de pontos compatíveis (pois envolveu a coleta de amostras de água subterrânea com intervalos entre as amostragens de até dez anos), campanhas de campo para a coleta de amostras em uma rede de poços de monitoramento pré-existente, medições de parâmetros in situ e análises químicas em laboratório. Os parâmetros analisados nesta pesquisa incluíram os íons maiores (cloreto, bicarbonato, sulfato, cálcio, magnésio, sódio, potássio) e brometo, além de pH e condutividade elétrica (CE). Esta escolha ocorreu para que fosse possível a eventual aplicação das razões iônicas, valiosa ferramen-

\footnotetext{
1 Instituto de Geociências - UFRJ - Professor Associado II do Departamento de Geologia Coordenador do Laboratório de Hidrogeologia (gerson@acd.ufrj.br).

2 Instituto de Geociências - UFRJ - Geólogo, Mestre em Geologia pelo Programa de Pós-Graduação em Geologia (viniciuscristo@geologia.ufrj.br).
} 
ta na identificação da origem e características da salinidade presente. Como resultado da pesquisa, verificou-se que a região de Itaipuaçu ainda não apresenta problemas significativos relacionados à migração da cunha salina, pelas evidências geoquímicas na interface salina. Observaram-se águas com diferentes processos geoquímicos dominantes, espacial e temporalmente: dissolução de sais do aerossol marinho, trocas iônicas, notadamente entre cálcio e sódio, processos evaporativos. Os resultados também indicam que a situação pode tornar-se crítica caso rompa-se o frágil equilíbrio hidrodinâmico local, como por exemplo, o contínuo aumento do bombeamento devido a forte expansão imobiliária e a própria expansão da ocupação urbana e obras civis associadas (canais, aterros, etc.).

Palavras-chave: Interface salina. Aquífero costeiro. Hidrogeoquímica. Itaipuaçu-Maricá. Rio de Janeiro.

\section{INTRODUÇÃO}

Segundo estimativas da ONU (HINRICHSEN, 1998), projeções de crescimento apontam que cerca de $75 \%$ da população do planeta (cerca de 6,3 bilhões de pessoas) habitará uma faixa de até $150 \mathrm{~km}$ de distância da costa até 2025 . Esta situação gera uma enorme pressão no sistema hídrico subterrâneo de muitas regiões costeiras. No Brasil a situação não é diferente, embora estudos hidrogeológicos/hidrogeoquímicos sobre essa temática sejam escassos no país. Alguns exemplos de estudos relevantes sobre a temática do comportamento dos aquíferos costeiros brasileiros podem ser encontrados em Bonilha \& Borges (2002), Costa et al. (2003), Paiva et al. (2003), Cabral e Paiva (2004), Silva Jr. \& Pizani (2003), Elis et al. (2004) e Cruz et al. (2006), dentre outros. Da leitura desses trabalhos observa-se uma grande diversidade de problemas nos aquíferos costeiros brasileiros, que vão desde aspectos relacionados à sua gestão, conflitos de uso, estudos sobre a salinização, etc. Nota-se em comum às referências consultadas que a coleta e interpretação de dados hidrogeoquímicos permite o emprego de um conjunto de técnicas e métodos de análise que aportam rica informação para a elaboração do modelo conceitual de funcionamento de tais corpos hídri$\cos$.

No estado do Rio de Janeiro, cuja costa vem sendo intensamente ocupada, seja por residências de verão ou empreendimentos turísticos, o uso dos aquíferos vem sendo feito praticamente com nenhum controle ou gerenciamento adequado. O perfil do uso de recursos hídricos na região costeira fluminense, em particular na costa a leste da capital (conhecida como Costa do Sol), modificou-se dramaticamente na última década, devido ao início, em vários municípios, da distribuição de água de mananciais de superfície pelas concessionárias vencedoras de licitações de privatização do tratamento e distribuição de água potável e coleta de efluentes domésticos. Tal mudança veio a reduzir, ao menos em um primeiro momento, alguns tipos de impactos sobre os aquíferos costeiros, pela diminuição do consumo de água subterrânea e o possível aporte de efluentes domésticos aos aquíferos, uma vez que a distribuição de água não veio acompanhada de um sistema de drenagem e tratamento de efluentes, na maioria dos casos.

A área de estudo está sujeita a sofrer com problemas comuns em áreas costeiras densamente povoadas como: um possível avanço da cunha salina, contaminação antrópica do aquífero e sobre-explotação. Devido à falta de estudos prévios de caráter hidrogeológico, tais possibilidades não haviam sido avaliadas anteriormente. $\mathrm{O}$ presente trabalho vem a jogar luz sobre os processos em curso e os possíveis impactos sobre o aquífero de Itaipuaçu. Desse modo, um melhor entendimento do comportamento do aquífero local, possibilitará que os stakeholders (grupos de interesse locais) possam tomar decisões que ajudem a minimizar os danos já sofridos e ajudem no planejamento das ações de explotação do recurso no futuro.

O objetivo principal deste trabalho é promover uma caracterização hidrogeoquímica do aquífero costeiro do distrito de Itaipuaçu, de modo a oferecer subsídios para a posterior elaboração de um modelo conceitual, com uma perspectiva do seu comportamento presente e o prognóstico de seu comportamento futuro. Adicionalmente, estudou-se a qualidade da água subterrânea através de alguns parâmetros que avaliam a sua potabilidade e adequação para o consumo humano, bem como os processos relacionados ao comportamento da cunha salina marinha no aquífero analisado. A comparação dos resultados deste trabalho com pesquisas realizadas anteriormente na área (ALVES, 2000; COSTA, 2001; PERALTA, 2009; ALMEIDA, 2009; SILVA JR. et al., 2005, entre outros) permitiu avaliar a evolução temporal das características hidroquímicas e de qualidade do aquífero. 


\section{CARACTERIZAÇÃo DA ÁREA DE ESTU-}

DO

A área de estudo está situada no distrito de Itaipuaçu, localizado a aproximadamente $60 \mathrm{~km}$ a leste da capital do estado do Rio de Janeiro e que faz parte do município de Maricá (Figura 1). A área estudada possui cerca de $36 \mathrm{~km}^{2}$, coincidindo com parte da região designada como Região Metropolitana do estado do Rio de Janeiro.

\section{Aspectos Fisiográficos}

O clima da região estudada é tropical, predominantemente quente e úmido, com estação seca pouco pronunciada no inverno e média de $1300 \mathrm{~mm}$ anuais de precipitação (CIDE, 1998). Os meses do verão são os mais chuvosos, sendo que mais de $70 \%$ da pluviometria anual ocorre entre outubro e março, e os meses de inverno correspondem ao período seco na região, conforme estudo da CPRM (2000). Na Baixada Litorânea, onde se encontra a área de estudo, as temperaturas médias são regularmente elevadas e suas variações são pequenas, oscilando entre $22 \mathrm{e}$ $23^{\circ} \mathrm{C}$. A partir de novembro até março as temperaturas médias ficam acima de $24^{\circ} \mathrm{C}$, com valores médios máximos de $32^{\circ} \mathrm{C}$, podendo chegar a máximas absolutas elevadas, próximas a $40^{\circ} \mathrm{C}$ (CIDE, 1998).

Os principais tipos de solos presentes na área de estudo são gleissolos e espodossolos e, secundariamente, neossolos flúvicos eutróficos (EMBRAPA, 1999). Maricá é rodeada por maciços costeiros de composição pré-cambriana e cristalina. O relevo é movimentado, com serras que chegam diretamente ao mar, entremeado por planícies costeiras. O município apresenta um grande complexo lagunar, com as lagoas de Maricá, Barra de Maricá, do Padre, Guarapina e Jaconé, além dos canais de Ponta Negra e de Itaipuaçu, que conectam as lagoas ao mar. Esse é um dos maiores complexos lagunares do estado, denominado Maricá-Guarapina, com rios, lagoas, riachos e brejos. $\mathrm{O}$ território municipal corresponde à bacia hidrográfica do grande sistema lagunar. Desta forma, praticamente todos os rios nascem e deságuam dentro do município. Seu principal rio é o Itapeba/Mombuca, que abastece o Centro da cidade e alguns bairros, através da ETA de Maricá. Maricá também tem canais artificiais com água salobra que ligam o complexo lagunar ao mar como os canais de Ponta Negra e Itaipuaçu. A abertura destes canais nos anos 1950 terminou com o regime natural de abertura de barra que acontecia entre Barra e Guaratiba, durante as épocas de mar alto no inverno, principalmente.

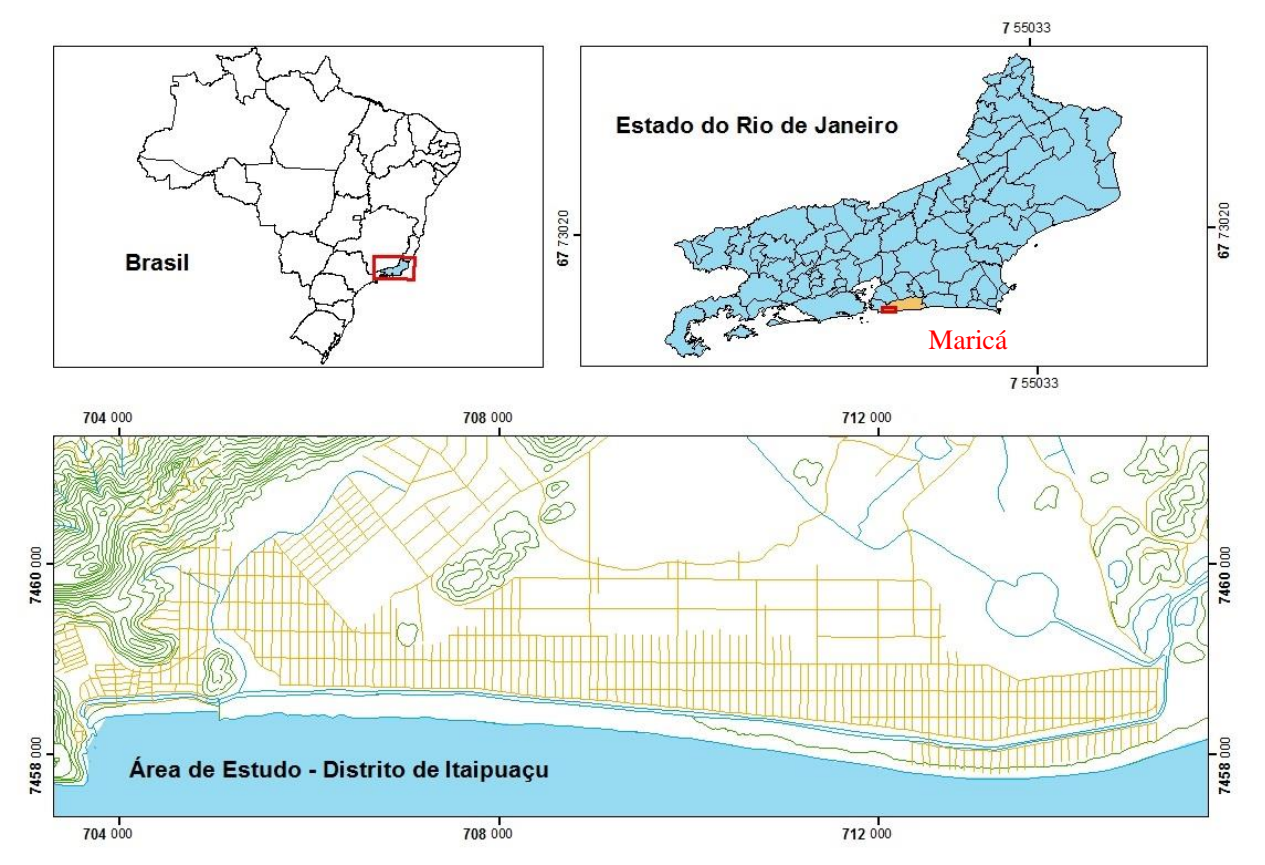

Figura 1 - Localização do distrito de Itaipuaçu no município de Maricá-RJ

Figure 1 - Location of Itaipuaçu in Maricá municipality, Rio de Janeiro State, Brazil 


\section{Geologia Regional e Local}

A região onde se situa a área de estudo situa-se no limite de dois importantes domínios tectono-magmáticos do estado do Rio de Janeiro: o Domínio Serra do Mar e o Domínio Região dos Lagos (CPRM, 2001). O Domínio Serra do Mar, que compreende o arcabouço geológico da área de estudo, ocupa a região ocidental da baixada de Maricá, correspondendo geograficamente à microplaca Serra do Mar. É composto por uma sucessão de arcos magmáticos mostrando marcante polaridade temporal e composicional de W para E. Caracteriza-se ainda por rochas supracrustais que sofreram metamorfismo de baixa pressão e alta temperatura, na fácies anfibolito, com abundante fusão parcial in situ (Complexo Paraíba do Sul). Esta unidade apresenta seus contatos bem definidos com os produtos finais da granitogênese brasiliana, representada por granitos pós-tectônicos que se distribuem especialmente no domínio Serra do Mar: o biotita-gnaisse porfiroblástico da Unidade Cassorotiba, unidade que constitui o embasamento local da área de estudo juntamente com o gnaisse facoidal (Figura 2).

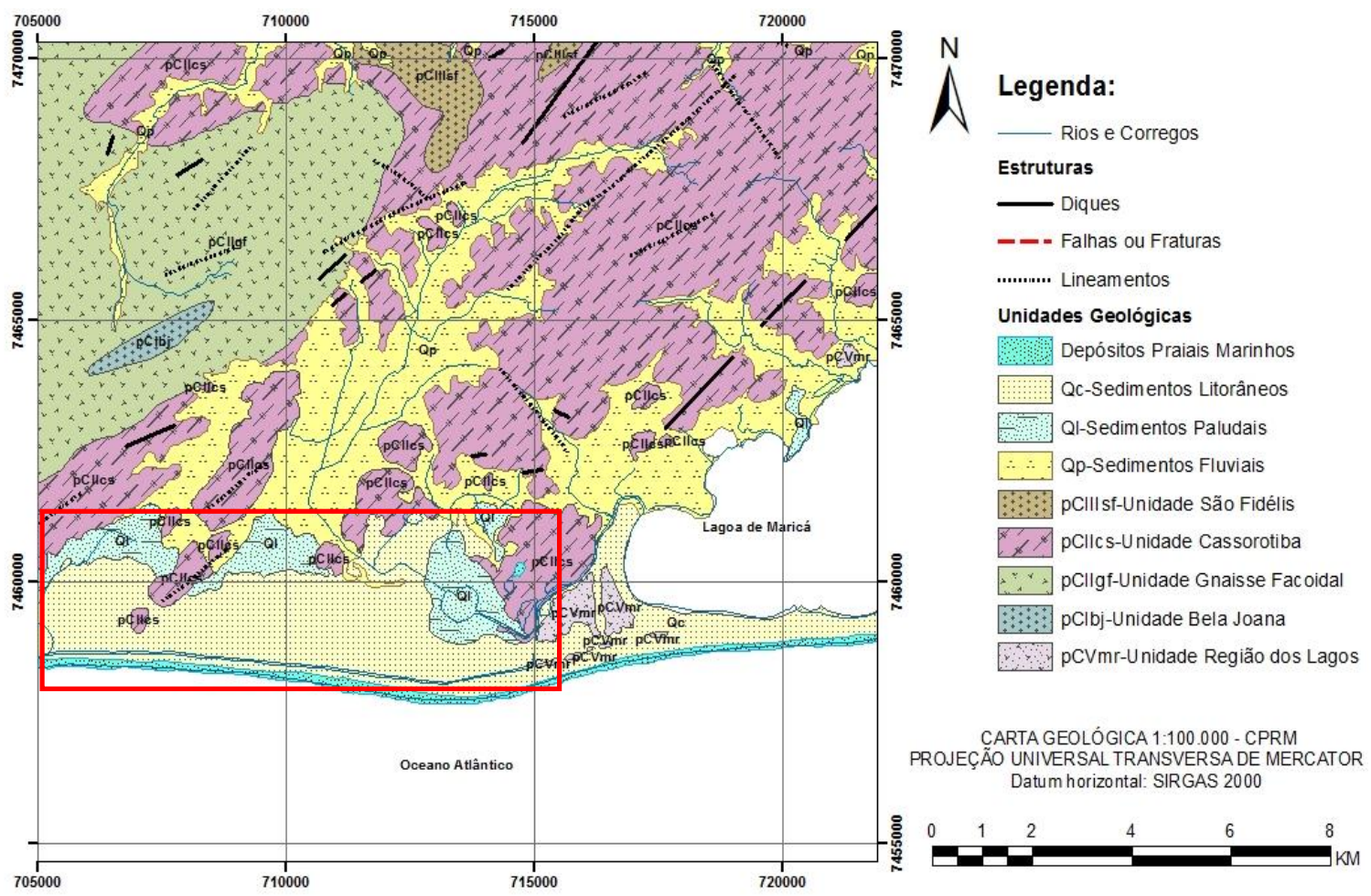

Figura 2 - Mapa de unidades geológicas da região de estudo. O retângulo vermelho indica a localização de Itaipu açu no município de Maricá-RJ (ver a Figura 3)

Figure 2 - Map with geological units in the study region. Red rectangle shows Itaipuaçu in Maricá municipality (see Figure 3 for reference)

Recobrindo os materiais do embasamento, ocorrem extensos arcos praiais, associados a cordões litorâneos (beach barriers) que, frequentemente, ocorrem em forma de duplos cordões, dispostos paralelamente entre si e separados por uma depressão estreita. A evolução geológica dos cordões costeiros do litoral do estado do Rio de Janeiro pode ser explicada pelos diversos períodos de alternâncias entre climas secos e úmidos, e de avanços e recuos do nível do mar, nos quais ocorreu a deposição de uma gama muito variável de sedimentos.
À retaguarda dos cordões litorâneos desenvolveu-se um complexo lagunar (sistema lagunar Maricá-Guarapina). A presente pesquisa limita-se aos aquíferos formados pelos cordões litorâneos, sedimentos litorâneos e paludais de idade quaternária, que ocupam a faixa litorânea bordejando irregularmente lagoas e lagunas da região. Esses depósitos são formados principalmente de areias quartzosas litorâneas razoavelmente selecionadas, cuja granulometria varia de média à grossa. 


\section{Hidrogeologia}

A hidrogeologia da região é caracterizada por um sistema freático a semiconfinado, constituído por materiais sedimentares do tipo granular, representando depósitos aluvionares costeiros, por vezes com porções de solo e rocha alterada (BARRETO et al., 2001). Os depósitos aluvionares são compostos principalmente por areias quartzosas e, subordinadamente, por areias siltosas e argilosas, que ocorrem nas proximidades das lagunas decorrentes da formação das baixadas litorâneas durante os últimos movimentos de variações do nível do mar.

A qualidade da água está geralmente relacionada ao ambiente em que se encontram os aquíferos e aos processos evolutivos locais. De um modo geral, a salinidade da água aumenta com a proximidade do litoral e, ao mesmo tempo, com a profundidade, sendo também controlada pela maior ou menor densidade de ocupação. Há notórias exceções, contudo, influenciadas por recargas distantes e/ou paleoáguas, que podem apresentar salinidades mais baixas mesmo em aquíferos mais profundos nas proximidades do mar (ALMEIDA \& SILVA JR., 2007).
As rochas do embasamento cristalino na área de estudo apresentam, em geral, baixa vocação aquífera, pois as águas quase sempre encontram-se salinizadas, exceto na fralda das encostas do fundo da planície costeira, onde há alguns poços produtores, em geral com pequenas vazões e características hidrogeoquímicas diferenciadas.

\section{METODOLOGIA}

O trabalho iniciou-se com uma pesquisa em banco de dados realizada com os resultados obtidos no âmbito de projetos anteriores e mais alguns poços (Figura 3) utilizados no trabalho de Costa (2001) e de Silva Jr. et al. (2005). Na atual pesquisa tentou-se obter o maior número de pontos para melhorar e distribuir de forma a cobrir a maior parte possível da área de estudo. Acrescentou-se uma nova área de estudo localizada no bairro do Recanto de Itaipuaçu, área próxima a duas serras (possíveis áreas de recarga do aquífero), ao canal do São Bento, exutório do sistema lagunar, e ao mar (ver Figura 4).

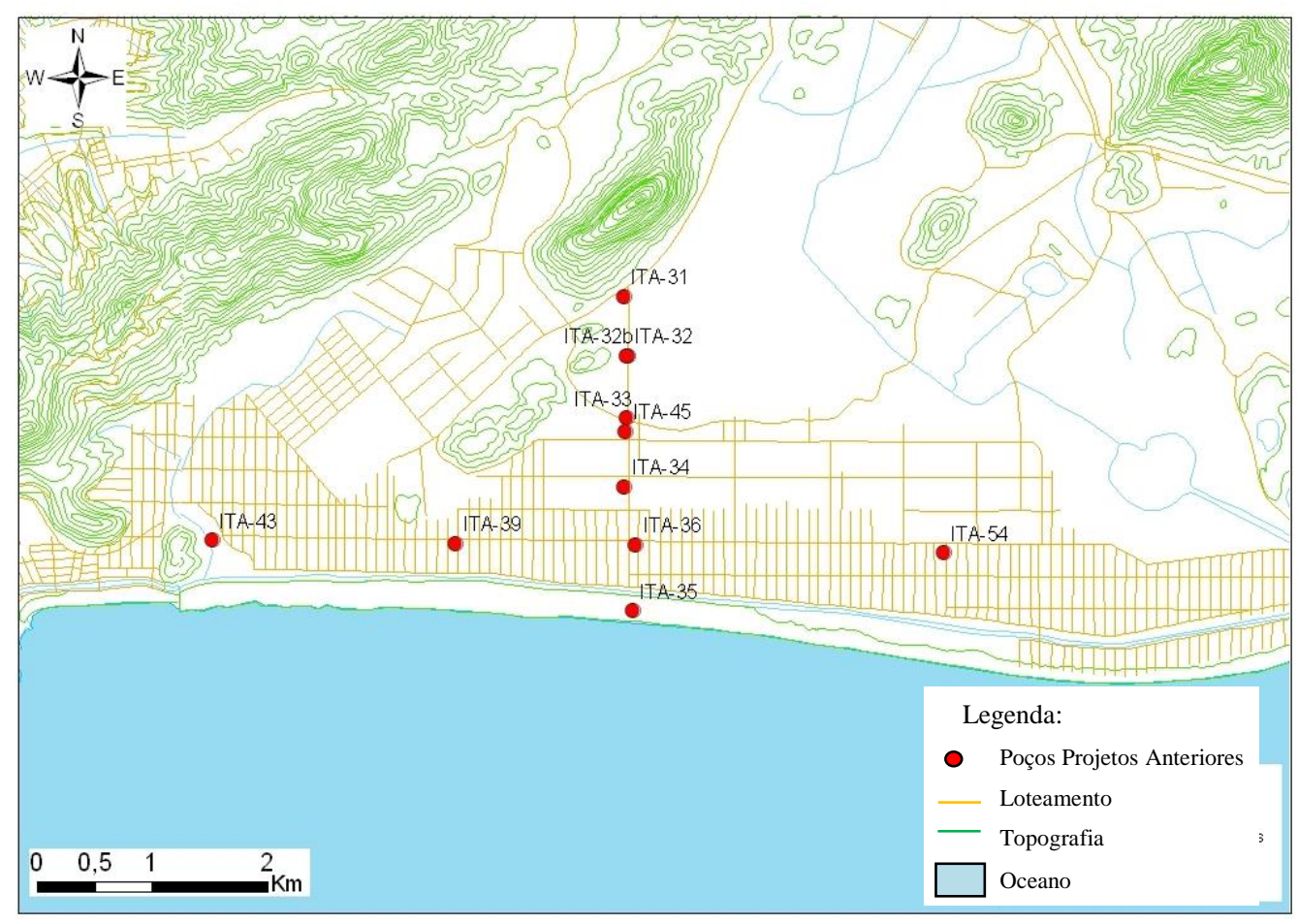

Figura 3 - Localização dos poços selecionados para amostragem oriundos de projetos anteriores (SILVA JR. et al., 2005; COSTA, 2001)

Figure 3 - Location of wells from previous projects selected for sampling and analyses (SILVA JR. et al., 2005; COSTA, 2001) 


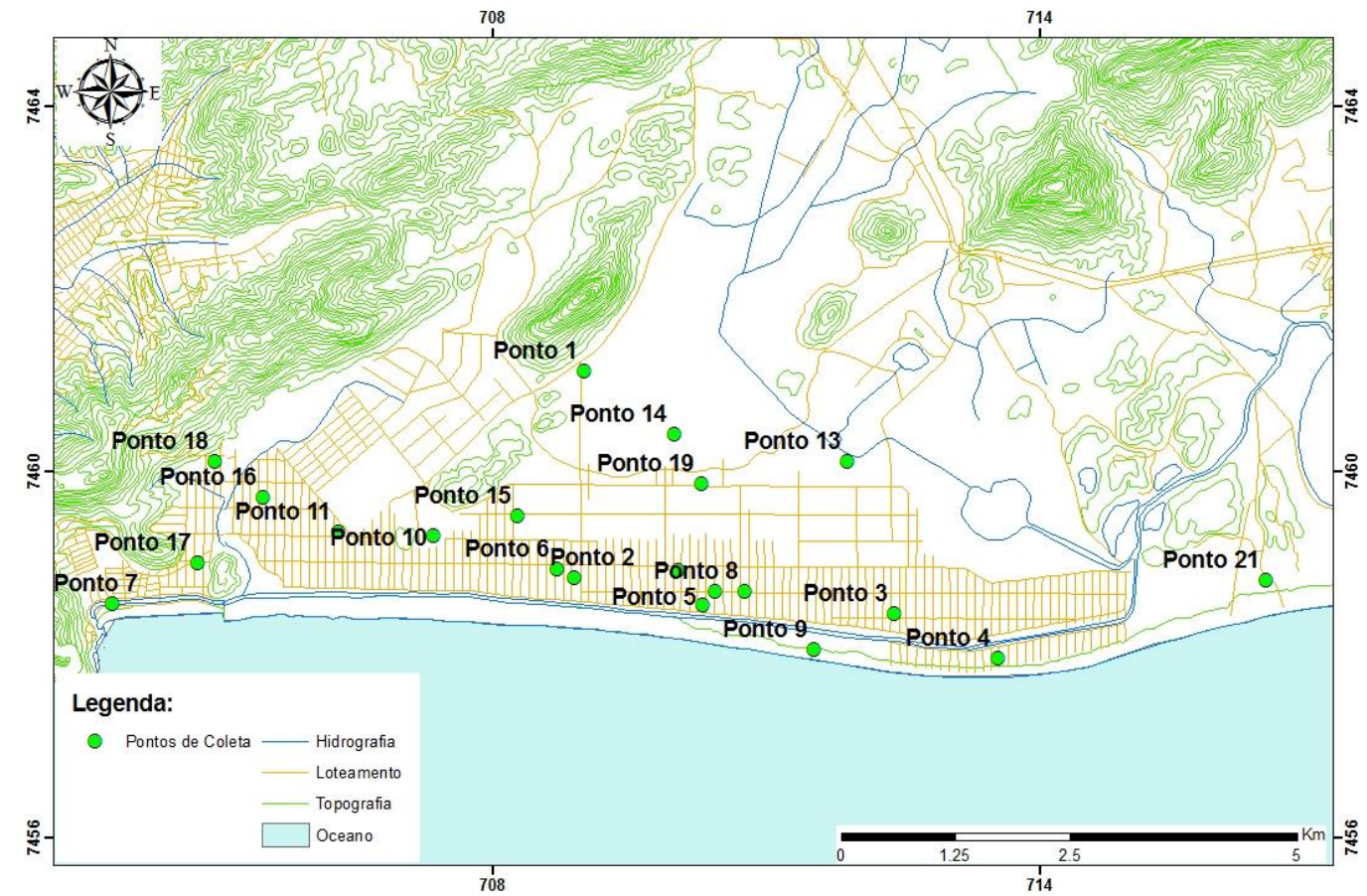

Figura 4 - Localização dos poços de estudados e amostrados no presente estudo (CRISTO \& SILVA JR., 2011; EGER, 2012) utilizados na elaboração dos resultados

Figure 4 - Locations of wells sampled and studied in the current study (CRISTO \& SILVA JR., 2011; EGER, 2012) used to build the results

Silva Jr. et al. (2005) coletaram dados em 81 poços na região de Itaipuaçu. A partir da base pré-existente, foram utilizados efetivamente nesta pesquisa dados hidroquímicos de 10 pontos de projetos anteriores; e em 2010 foram realizadas coletas em 11 novos poços para a pesquisa atual, conforme observa-se nas figuras 3 e 4 (CRISTO \& SILVA JR., 2011). Após este período, realizaram-se amostragens e análises complementares em mais 10 poços que permitiram tornar mais confiável o modelo conceitual hidrogeológico da área (EGER, 2012). A escolha dos poços teve como critérios norteadores a confiabilidade dos dados, erro de balanço iônico de até $10 \%$ e seu posicionamento geográfico e estratigráfico, de modo a permitir a interpretação hidrogeoquímica. Portanto, a base de dados disponível contou com 31 poços que foram amostrados e analisados para vários parâmetros químicos, além de análises físico-químicas in situ.

As campanhas de campo foram realizadas em agosto de 2010, abril e julho de 2011 e janeiro de 2012) para análise de parâmetros físicoquímicos in situ (Condutividade elétrica, $\mathrm{pH}$, Eh e temperatura), com o uso de instrumentos portáteis da marca Hanna (HI98120, HI98311 e HI98128). Em seguida, realizou-se a coleta de amostras, para posterior análise química em laboratório. As amostras foram analisadas no LaDA (Laboratório de Desenvolvimento Análitico) do Instituto de Química da UFRJ (Cálcio, Magnésio, Potássio, Sódio, Cloreto, Brometo, Sulfato e Bicarbonato). Nas análises realizadas em 2010 e 2012 os parâmetros químicos foram determinados por:

a) Espectrofotometria de absorção atômica (K, Na) e Espectrometria de Emissão com Plasma Indutivamente Acoplado (ICP-OES) - demais metais (cátions);

b) Fotometria por Emissão de Chama, para os parâmetros $\mathrm{Cl}^{-}, \mathrm{F}^{-}, \mathrm{PO}_{4}^{-}, \mathrm{NO}_{3}^{-}$, e $\mathrm{SO}_{4}{ }^{-}$, além de $\mathrm{NH}_{4}^{+}$;

c) Cromatografia de Íons - ânions em geral;

Foi realizada a tentativa de avaliar a assinatura geoquímica do aquífero costeiro de Itaipuaçu e as modificações que porventura pudessem ter ocorrido no período. A partir dos resultados das análises químicas foram construídos diagramas diversos (Piper, dispersão, etc.) no software AquaChem (versão 5.1, da Schlumberger Water Services S.A.) e elaborados gráficos nos softwares Excel e Grapher, para fins de caracterização hidrogeoquímica da região e comparação com os dados hidrogeoquímicos dos projetos anteriores.

O estudo das razões iônicas é de extrema importância para classificação e interpretação da hidrogeoquímica de aquíferos costeiros, permitindo, inclusive, o estudo da origem da salinidade e 
diferenciar a gênese da água subterrânea (APPELO \& POSTMA, 2005; CABRAL e PAIVA, 2004; GHABAYEN et al., 2006; ISA et al., 2012; PARK et al., 2012; RINA et al., 2013; RINA et al., 2013a). No distrito de Itaipuaçu foram escolhidas as razões iônicas de maior significado para a representação das condições locais. Algumas das razões que permitem inferir $o$ comportamento de aquíferos sob influência marinha foram empregadas no presente trabalho, como $\quad \mathrm{rMg} / \mathrm{rCa}, \quad \mathrm{rNa} / \mathrm{rCl}, \quad \mathrm{rCl} / \mathrm{rHCO}_{3}$ e $\mathrm{rCl}_{/} \mathrm{rHCO}_{3} / \mathrm{rCl}$. Particularmente, a razão iônica $\mathrm{rCl} / \mathrm{rBr}$ tem grande significado no estudo da origem da salinidade e teve uma avaliação detalhada.

\section{RESULTADOS E DISCUSSÕES}

As águas subterrâneas na área de estudo foram objeto de levantamento e caracterização hidrogeoquímica pouco mais de uma década anteriormente a presente pesquisa (SILVA JR. et al., 2005; COSTA, 2001). Desse modo, foi possível, além de apontar e identificar os principais aspectos quanto a assinatura geoquímica, efeitos da interface salina e demais processos existentes, também realizar a avaliação da situação sob a perspectiva de sua evolução temporal, ao longo do período analisado. As tabelas 1 e 2 mostram, respectivamente, os resultados das análises químicas realizadas no período anterior e o atual, e as figuras 3 e 4 apresentam a localização dos poços utilizados no presente estudo.

Com a comparação dos resultados das análises químicas dos anos de 2000 e 2010/2012, não se observou mudança significativa das carac- terísticas geoquímicas, na salinidade do aquífero ou indicações de mudanças nos processos geoquímicos ali presentes, que poderiam dever-se ao já citado incremento da atividade humana e consequentes impactos nos aquíferos dessa região.

O diagrama de Piper (Figura 5) representa a população de amostras de 2000 e de 2010/2012. Em relação à classificação das águas do aquífero costeiro de Itaipuaçu, este manteve ao longo do período a característica de uma água predominantemente cloretada-sódica, com alguma dispersão em torno da composição da água marinha. A única exceção corre por conta do ponto 8 , que tem teores relativamente elevados de bicarbonato e de cálcio, o que pode ser decorrência da presença local de depósitos de conchas, comuns na área de estudo.

As águas analisadas em 2000 e 2010/2012 corresponderam a águas de consumo humano, pouco salinizadas, à exceção da amostra do poço ITA-36, poço de investigação com cerca de $40 \mathrm{~m}$ de profundidade, cuja água apresentou elevada salinidade. Com efeito, em relação às amostras pretéritas, apenas a amostra ITA-36, não computada nos gráficos apresentados, apresentou valores acima do máximo permitido pela legislação vigente para vários parâmetros, com composição muito próxima à da água marinha. Procurou-se comparar a água salgada do substrato inferior do aquífero profundo com a água marinha atual. Comprovou-se a grande similitude entre ambas (Figura 6). À exceção da amostra do Ponto 9, que tem valores de cloreto e sódio acima do permitido, nenhuma das demais amostras de água subterrânea coletadas nas novas campanhas (2010/2012) está fora dos limites estabelecidos por lei (Portaria MS 2914/2011).

Tabela 1 - Compostos mensurados nas campanhas de 2000, segundo Silva Jr et al. (2005). Valores dos íons dissolvidos em $\mathrm{mg} / \mathrm{L}$

Table 1 - Measured compounds in year 2000 field survey, according to Silva Jr et al. (2005). Ion concentrations in $\mathrm{mg} / \mathrm{L}$

\begin{tabular}{ccccccccccc}
\hline ID & $\mathbf{M g}^{\mathbf{2 +}}$ & $\mathbf{C a}^{2+}$ & $\mathbf{C l}^{-}$ & $\mathbf{N a}^{+}$ & $\mathbf{H C O}^{-}$ & $\mathbf{K}^{+}$ & $\mathbf{S O}_{4}{ }^{-2}$ & $\mathbf{B r}^{-}$ & $\mathbf{p H}$ & $\mathbf{C E}(\boldsymbol{\mu S} / \mathbf{c m})$ \\
\hline ITA 31 & 7,76 & 4,52 & 102 & 75,2 & 55,3 & 2,1 & 20,1 & 0,36 & 6,22 & 460 \\
ITA 32 & 16,13 & 5,21 & 199 & 127 & 25,2 & 3,5 & 44,3 & 0,54 & 5,77 & 756 \\
ITA 33 & 1,73 & 3,96 & 27,24 & 14,4 & 15,3 & 2,1 & 1,8 & 0,13 & 5,75 & 114 \\
ITA 34 & 0,89 & 1,03 & 13,34 & 6,7 & 8,3 & 1 & 0,1 & 0,06 & 5,66 & 61 \\
ITA 35 & 2,37 & 5,8 & 46,3 & 35,1 & 14,7 & 9,9 & 23,5 & 0,05 & 5,4 & 241 \\
ITA 36 & 1276 & 393,9 & 17284 & 9590 & 132,1 & 400 & 2391 & 49,8 & 7,52 & 35500 \\
ITA 39 & 3,03 & 16,86 & 28,21 & 17,2 & 8,9 & 9,7 & 15,3 & 0,05 & 6,46 & 237 \\
ITA 43 & 2,66 & 7,8 & 28,37 & 20,4 & 1,9 & 6 & 35,2 & 0,05 & 4,72 & 179 \\
ITA 45 & 1,43 & 3,87 & 20,22 & 12,54 & 19,2 & 1,28 & 0,4 & 0,05 & 6,42 & 109,6 \\
ITA 54 & 1,81 & 0,85 & 19,04 & 13,02 & 6,4 & 2,58 & 8,2 & 0,07 & 5,85 & 112,8 \\
VMP* & $\mathrm{NE} * *$ & $\mathrm{NE}$ & 250 & 200 & $\mathrm{NE}$ & $\mathrm{NE}$ & 250 & $\mathrm{NE}$ & & \\
\hline
\end{tabular}

* VMP - Valores Máximos Permitidos, segundo a Portaria MS 2914/2011 - Ministério da Saúde. **NE - Não Especificado 
Tabela 2 - Compostos mensurados nas campanhas de 2010 e 2012 (CRISTO \& SILVA JR., 2011; EGER, 2012). Valores dos íons dissolvidos em $\mathrm{mg} / \mathrm{L}$

Table 2 - Measured compounds in 2010 and 2012 surveys (CRISTO \& SILVA JR., 2011; EGER, 2012). Ion concentrations in $\mathrm{mg} / \mathrm{L}$

\begin{tabular}{ccccccccccc}
\hline ID & $\mathbf{M g}^{2+}$ & $\mathbf{C a}^{2+}$ & $\mathbf{C l}^{-}$ & $\mathbf{N a}^{+}$ & $\mathbf{H C O}^{-}$ & $\mathbf{K}^{+}$ & $\mathbf{S O}^{2-}$ & $\mathbf{B r}^{-}$ & $\mathbf{p H}$ & $\mathbf{C E}(\boldsymbol{\mu S} / \mathbf{c m})$ \\
\hline Ponto 1 & 8,72 & 7,31 & 105,03 & 137,65 & 71,50 & 1,48 & 49,95 & 0,82 & 6,12 & 1030 \\
Ponto 2 & 2,46 & 7,53 & 31,68 & 32,44 & 35,75 & 8,3 & 23,58 & 0,05 & 5,75 & 313 \\
Ponto 3 & 2,85 & 12,18 & 27,83 & 31,19 & 35,75 & 7,16 & 11,93 & 0,03 & 5,22 & 202 \\
Ponto 4 & 1,45 & 0,96 & 25,31 & 24,61 & 35,75 & 5,57 & 13,26 & - & 5,04 & 240 \\
Ponto 5 & 1,91 & 7,79 & 26,04 & 21,33 & 35,75 & 3,75 & 11,05 & - & 5,5 & 334 \\
Ponto 6 & 2,50 & 10,67 & 30,23 & 37,44 & 35,75 & 9,66 & 22,66 & - & 5,3 & 367 \\
Ponto 7 & 2,65 & 12,08 & 46,15 & 46,81 & 35,75 & 5,8 & 36,3 & - & 8,4 & 426 \\
Ponto 8 & 2,66 & 13,40 & 24,10 & 16,90 & 348,75 & 3,80 & 0,17 & 0,02 & 5,96 & 199 \\
Ponto 9 & 17,40 & 17,70 & 353,00 & 253,00 & 92,00 & 8,54 & 2,17 & 0,04 & 7,25 & 788 \\
Ponto 10 & 4,03 & 3,46 & 42,70 & 37,40 & 16,40 & 6,31 & 0,27 & 0,05 & 5,18 & 314 \\
Ponto 11 & 3,48 & 22,30 & 47,20 & 37,60 & 38,20 & 7,01 & 0,19 & 0,04 & 6,00 & 365 \\
Ponto 12 & 2,56 & 12,60 & 49,80 & 44,70 & 2,22 & 9,53 & 45,70 & 0,02 & 4,55 & 248 \\
Ponto 13 & 1,26 & 2,84 & 23,20 & 9,67 & 13,70 & 0,99 & 0,23 & 0,06 & 5,95 & 101 \\
Ponto 14 & 1,03 & 3,04 & 21,40 & 9,34 & 14,30 & 0,90 & 0,09 & 0,06 & 5,86 & 120 \\
Ponto 15 & 2,43 & 4,60 & 38,30 & 20,30 & 17,30 & 1,73 & 1,38 & 0,14 & 5,75 & 193 \\
Ponto 16 & 2,90 & 7,18 & 37,10 & 33,30 & 8,95 & 7,83 & 33,40 & 0,09 & 5,47 & 284 \\
Ponto 17 & 5,50 & 14,10 & 80,80 & 53,00 & 2,09 & 6,75 & 90,90 & 0,18 & 4,80 & 166 \\
Ponto 18 & 7,00 & 6,11 & 96,20 & 79,50 & 38,60 & 1,63 & 25,40 & 0,32 & 5,90 & 515 \\
Ponto 19 & 1,42 & 5,46 & 21,70 & 11,60 & 18,80 & 1,46 & 0,22 & 0,08 & 6,10 & 130 \\
Ponto 20 & 3,36 & 1,83 & 49,00 & 28,20 & 1,97 & 2,05 & 11,30 & 0,17 & 4,50 & 253 \\
Ponto 21 & 2,70 & 4,50 & 36,30 & 19,55 & 4,75 & 1,17 & 9,76 & 0,12 & 4,70 & 209 \\
VMP* & NE** & NE & 250 & 200 & NE & NE & 250 & NE & - & - \\
\hline * VMP - Valores Máximos Permitidos, segundo a Portaria MS $2914 / 2011-$ Ministério da Saúde. **NE-Não Especificado
\end{tabular}

Nas tabelas 3 e 4, bem como nos gráficos das Figuras 7 a 12, são apresentadas as razões iônicas obtidas nas amostras processadas, a partir dos valores expressos em meq/L.

Tabela 3 - Razões Iônicas calculadas com dados do ano 2000 (Silva Jr. et al. 2005)

Table 3 - Calculated ion ratios with year 2000 data (Silva Jr. et al. 2005)

\begin{tabular}{ccccc}
\hline ID & $\mathbf{r M g} / \mathbf{r C a}$ & $\mathbf{r C l} / \mathbf{r B r}$ & $\mathbf{r N a} / \mathbf{r C l}$ & $\mathbf{r C l} / \mathbf{r H C O} \mathbf{3}$ \\
\hline ITA 31 & 2,826 & 637,700 & 1,138 & 1,585 \\
ITA 32 & 5,096 & 829,426 & 0,985 & 6,785 \\
ITA 33 & 0,719 & 471,609 & 0,816 & 1,530 \\
ITA 34 & 1,422 & 500,407 & 0,775 & 1,381 \\
ITA 35 & 0,673 & 2084,152 & 1,170 & 2,706 \\
ITA 36 & 5,332 & 781,148 & 0,856 & 112,412 \\
ITA 39 & 0,296 & 1269,847 & 0,941 & 2,723 \\
ITA 43 & 0,561 & 1277,050 & 1,110 & 12,829 \\
ITA 45 & 0,608 & 910,185 & 0,957 & 0,905 \\
ITA 54 & 3,505 & 3626,849 & 1,055 & 15,143 \\
\hline
\end{tabular}


Tabela 4 - Razões Iônicas calculadas: dados do ano 2010 (CRISTO \& SILVA JR., 2011) e 2012 (EGER, 2012)

Table 4 - Calculated ion ratios with year 2010 (CRISTO \& SILVA JR., 2011) and 2012 data

\begin{tabular}{ccccc}
\hline ID & rMg/rCa & rCl/rBr & rNa/rCl & rCl/ rHCO3 \\
\hline Ponto 1 & 1,988 & 288,282 & 2,014 & 2,524 \\
Ponto 2 & 0,544 & 1426,046 & 1,574 & 1,523 \\
Ponto 3 & 0,390 & 2087,903 & 1,722 & 1,338 \\
Ponto 4 & 2,517 & - & 1,494 & 1,217 \\
Ponto 5 & 0,409 & - & 1,259 & 1,252 \\
Ponto 6 & 0,391 & - & 1,903 & 1,453 \\
Ponto 7 & 0,366 & - & 1,559 & 2,218 \\
Ponto 8 & 0,331 & 319,070 & 1,078 & 0,119 \\
Ponto 9 & 1,638 & 366,128 & 1,101 & 6,593 \\
Ponto 10 & 1,941 & 355,945 & 1,346 & 4,474 \\
Ponto 11 & 0,260 & 559,122 & 1,224 & 2,123 \\
Ponto 12 & 0,339 & 700,532 & 1,379 & 38,546 \\
Ponto 13 & 0,379 & 856,006 & 0,641 & 2,910 \\
Ponto 14 & 0,565 & 789,591 & 0,671 & 2,571 \\
Ponto 15 & 0,880 & 615,728 & 0,815 & 3,804 \\
Ponto 16 & 0,673 & 938,215 & 1,379 & 7,123 \\
Ponto 17 & 0,650 & 1010,32 & 1,008 & 66,430 \\
Ponto 18 & 1,909 & 676,618 & 1,270 & 4,282 \\
Ponto 19 & 0,433 & 626,157 & 0,822 & 1,983 \\
Ponto 20 & 3,060 & 648,732 & 0,884 & 42,740 \\
Ponto 21 & 1,000 & 680,838 & 0,828 & 13,132 \\
\hline
\end{tabular}

As razões $\underline{\mathrm{rMg} / \mathrm{rCa}}$ em 2000 e 2010/2012 apresentam grande semelhança na sua distribuição (Figura 7): a maior parte das águas subterrâneas rasas que constituem os aquíferos explotados na área de estudo possui razões $\mathrm{rMg} / \mathrm{rCa}$ dentro da faixa normal de águas continentais. As exceções, com valores maiores dessa razão (excesso de magnésio), constituem pontos que estão quase todos situados no limite das áreas sedimentares com os materiais cristalinos das serras adjacentes (Pontos 1, 10, 18, 20, ITA-31, e ITA-32). Isso pode advir da contribuição da hidrólise de minerais máficos das rochas cristalinas, abundantes no granito Cassorotiba. Nesse sentido, é possível que, nas porções do aquífero nas quais a água subterrânea apresenta um maior tempo de residência, próximas à rocha-fonte (granitos) o intemperismo da biotita, piroxênio e anfibólio, por exemplo, aporte quantidades importantes de $\mathrm{Mg}$ à água. O Ponto 4, muito próximo ao mar, e o Ponto 9 (aquífero profundo com possível paleoágua) são também pontos com valores mais elevados de magnésio.

Com relação à razão $\mathrm{rNa} / \mathrm{rCl}$ pode-se dizer que no ano 2000, de um modo geral, as amostras estão distribuídas ao longo da linha de diluição da água marinha (Figura 8), enquanto as amostras do ano 2010-2012 tem uma maior dispersão. Observa-se que os valores de cloreto apresentam um valor mínimo da ordem de 0,5-0,6 meq/L, independentemente do teor de sódio, o que pode ser explicado pelo caráter praticamente não reativo desse íon, conforme a linha de melhor ajuste observada na figura 8 . Os teores de cloreto mantêmse acima de um determinado patamar que seria determinado pelo aporte mínimo da água de recarga, que varia muito mais no caso do sódio, pelas reações de troca iônica em argilominerais e outras reações. Outro fato relevante que se observa na figura 8 é o excesso de sódio, tanto maior quanto maior a concentração de sais na água subterrânea, até que começa a haver o esperado alinhamento com os valores da água marinha, para concentrações salinas mais elevadas. $\mathrm{O}$ pequeno excesso de sódio com respeito à linha de diluição da água marinha observado na figura 8 pode representar um possível aporte desse íon a partir da hidrólise dos minerais (feldspato sódico, principalmente) dos sedimentos e arcabouço continentais. 


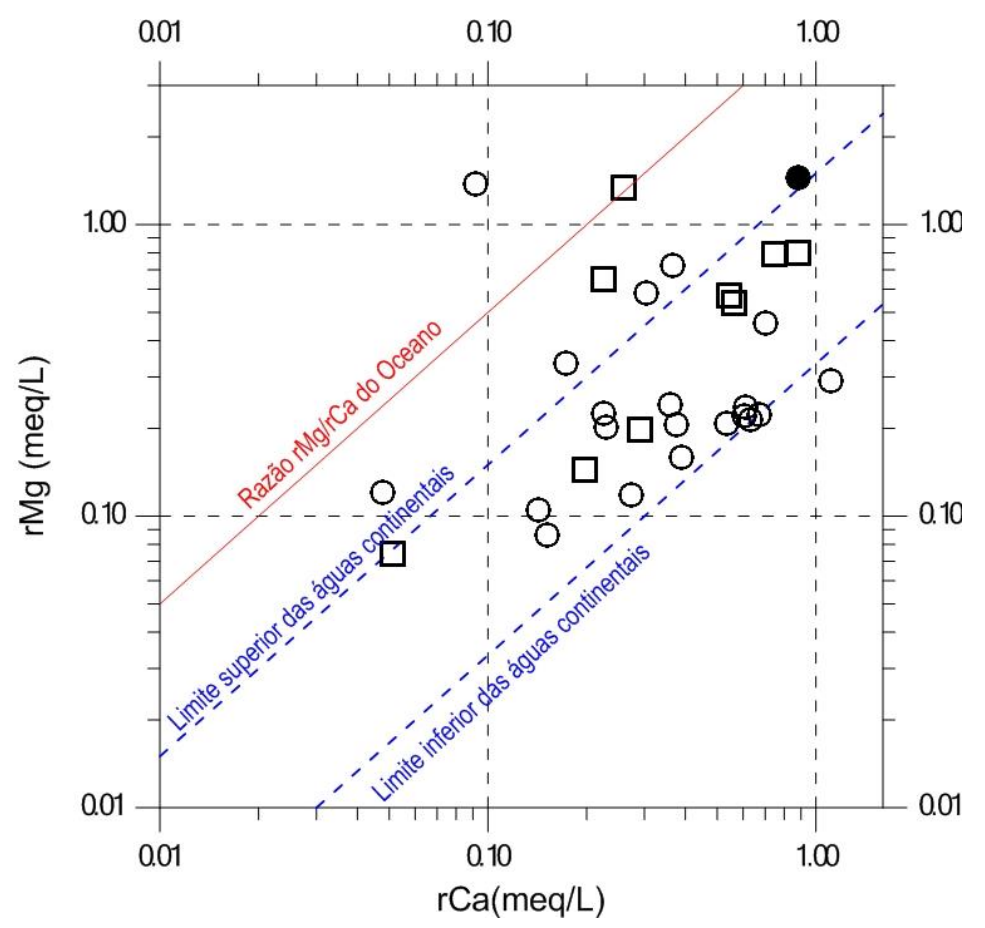

Figura 7 - Razão Iônica Mg/Ca. Quadrados: campanha de 2000; Círculos: campanha de 20102012; Círculo negro: Amostra do aquífero profundo (Ponto 9).CUSTODIO \& LLAMAS, 1976

Figure 7 - Mg/Ca Ion ratio. Squares: year 2000 survey; circles: years 2010-2012 surveys; black circle: deep aquifer sample (Point 9). CUSTODIO \& LLAMAS, 1976

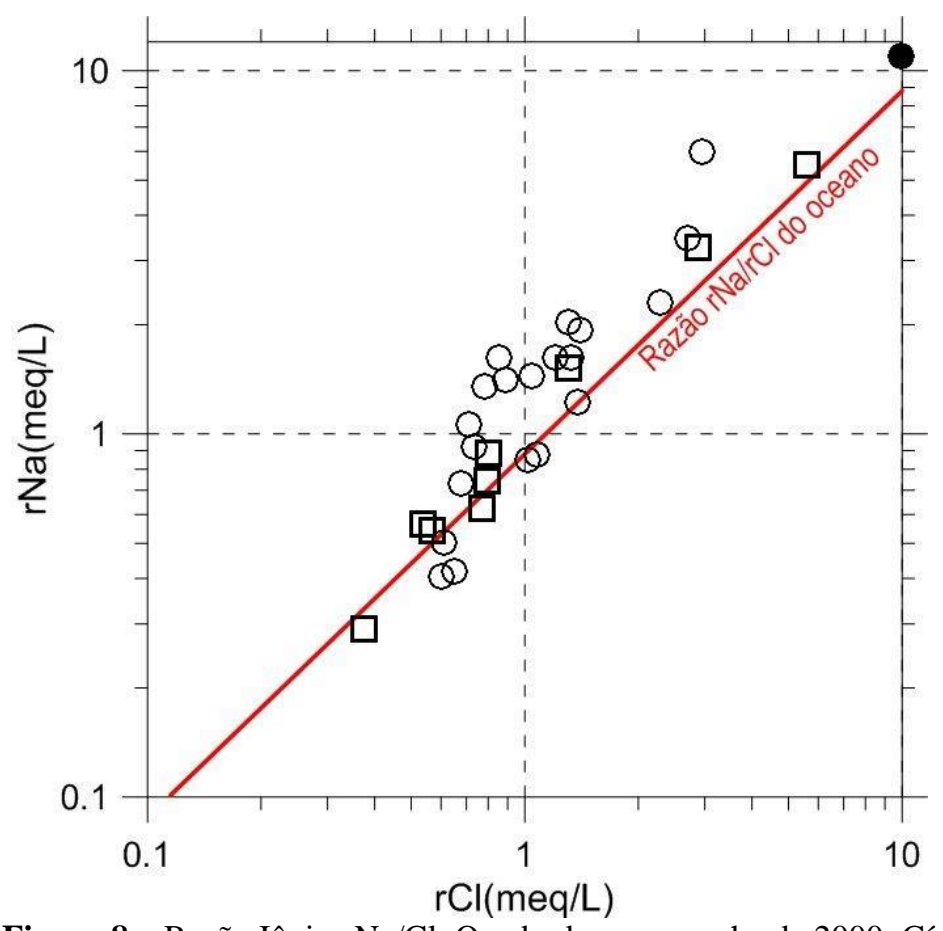

Figura 8 - Razão Iônica Na/Cl. Quadrados: campanha de 2000; Círculos: campanha de 2010-2012; Círculo negro: Amostra do aquífero profundo (Ponto 9). CUSTODIO \& LLAMAS, 1976

Figure 8 - Na/Cl Ion ratio. Squares: year 2000 survey; circles: years 2010-2012 surveys; black circle: deep aquifer sample (Point 9). CUSTODIO \& LLAMAS, 1976

A razão $\underline{\mathrm{rCl} / \mathrm{rHCO}_{3}}$ (Figura 9) apresenta em geral bastante dispersão nos resultados, que embora compatíveis com águas doces continentais estão, na média das amostras, próximos ao que é considerado o limite máximo desse ambiente, ou inclusive acima, como no caso do Poço 9 (aquífe- 
ro profundo). A razão $\mathrm{rCl} / \mathrm{rHCO}_{3}$ vs. $\mathrm{rCl}$ (Figura 10) reforça o resultado da observação da figura 9 , com uma definição da origem continental das águas subterrâneas locais.

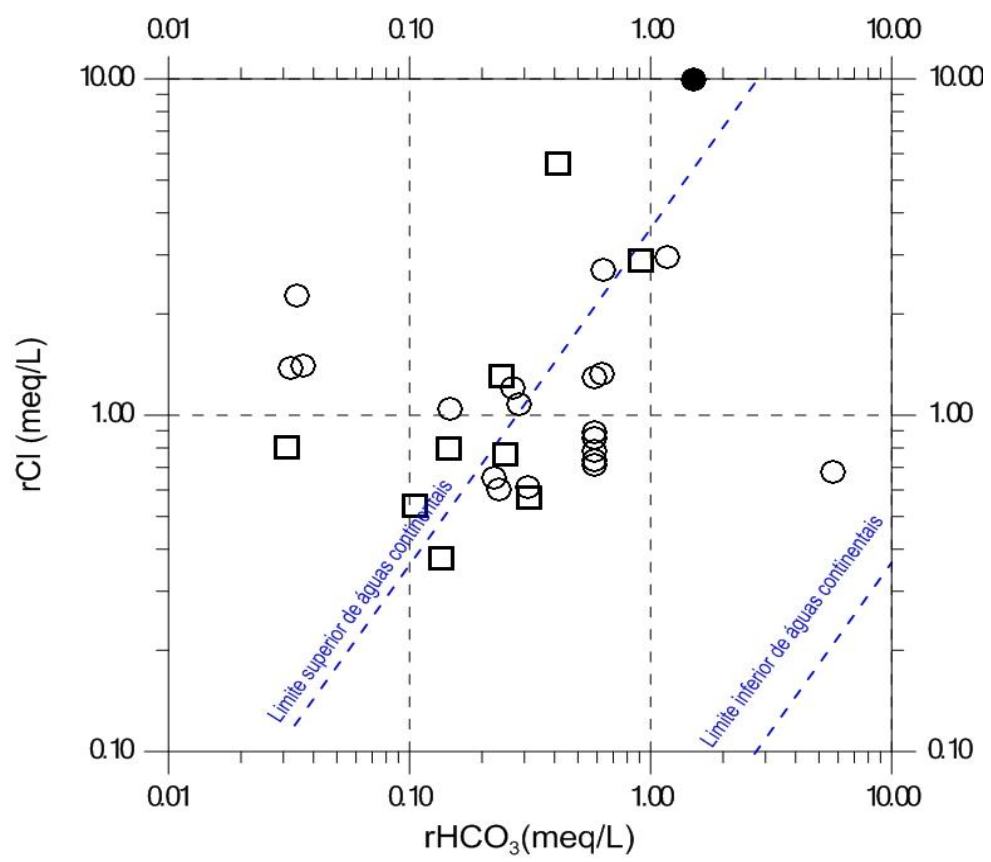

Figura 9 - Razão Iônica $\mathrm{Cl} / \mathrm{HCO}_{3}$. Quadrados: campanha de 2000; Círculos: campanha de 2010-2012; Círculo negro: Amostra do aquífero profundo (Ponto 9). CUSTODIO \& LLAMAS, 1976

Figure $9-\mathrm{Cl} / \mathrm{HCO}_{3}$ Ion ratio. Squares: year 2000 survey; circles: years 2010-2012 surveys; black circle: deep aquifer sample (Point 9). CUSTODIO \& LLAMAS, 1976

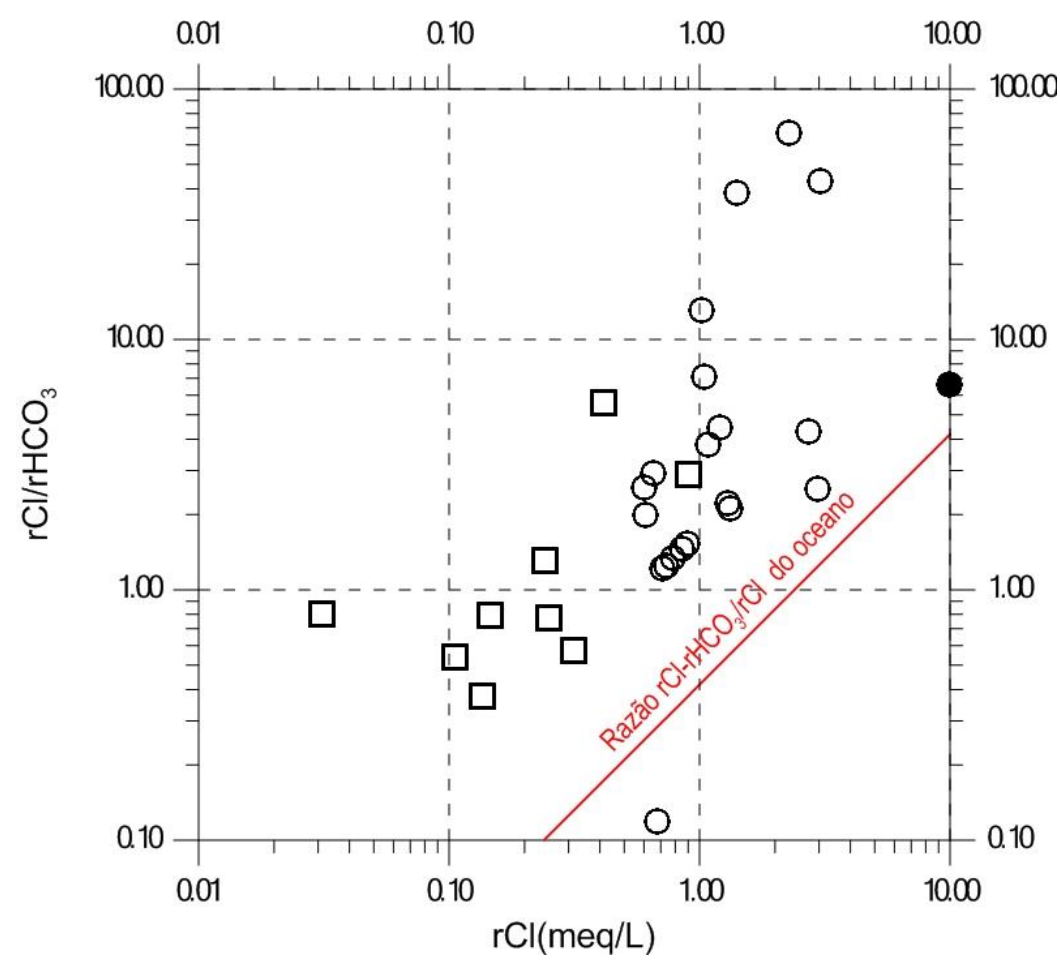

Figura 10 - Razão Iônica Cl- $\mathrm{HCO}_{3} / \mathrm{Cl}$. Quadrados: campanha de 2000; Círculos: campanha de 2010-2012; Círculo negro: Amostra do aquífero profundo (Ponto 9). CUSTODIO \& LLAMAS, 1976

Figure 10 - $\mathrm{Cl}-\mathrm{HCO}_{3} / \mathrm{Cl}$ Ion ratio. Quadrados: campanha de 2000; Círculos: campanha de 2010-2012; Círculo negro: Amostra do aquífero profundo (Ponto 9). CUSTODIO \& LLAMAS, 1976 
A razão $\mathrm{rCl} / \mathrm{rBr}$ é uma das mais úteis relações iônicas, pois ambos íons são pouco reativos auxiliando como poucos na interpretação de ambientes de formação pelo seu caráter próximo ao ideal como traçadores. Nas amostras da área de estudo há um claro alinhamento das águas com a linha de diluição da água marinha (Figura 11). Dessa forma, embora outros indicadores possam mostrar sinais contraditórios quanto à influência marinha sobre a água subterrânea local, tal relação mostra claramente a importância da água do mar na constituição dos aquíferos de Itaipuaçu. As exceções correm por conta dos Pontos 1,8 e 10, com um claro excesso de brometo com respeito a águas marinhas, sendo simultaneamente águas pouco mineralizadas; e o ponto 9 , representante do aquífero profundo. Segundo se observa na figura 4, as amostras dos pontos 1,8 e 10 estão localizadas na faixa de ocorrência de águas mais afastadas do mar e em áreas intensamente urbani- zadas: isto leva a interpretação de que há contaminação antrópica devido a grande quantidade de fossas sépticas cavadas sem supervisão técnica e aporte de águas doces de efluentes domésticos e, inclusive, oriundas de caminhões-pipa, por exemplo. Na figura 12 observa-se que tais amostras tem uma assinatura química com respeito à razão $\mathrm{rCl} / \mathrm{rBr}$ por $\mathrm{Cl}$, que as relaciona a áreas costeiras poluídas ou áreas interiores (ALCALÁ \& CUSTODIO, 2008), em consonância com sua situação geográfica local.

O ponto 9 (aquífero profundo) pode ser uma água de origem e comportamento geoquímico distintos das demais águas locais, hipótese reforçada com a observação das figuras 11 e 12. A possível filiação com águas poluídas por atividades agrícolas pode indicar o seu caráter relicto, uma paleoágua recarregada em tempos pretéritos, quando a área tinha atividade essencialmente agropecuária.

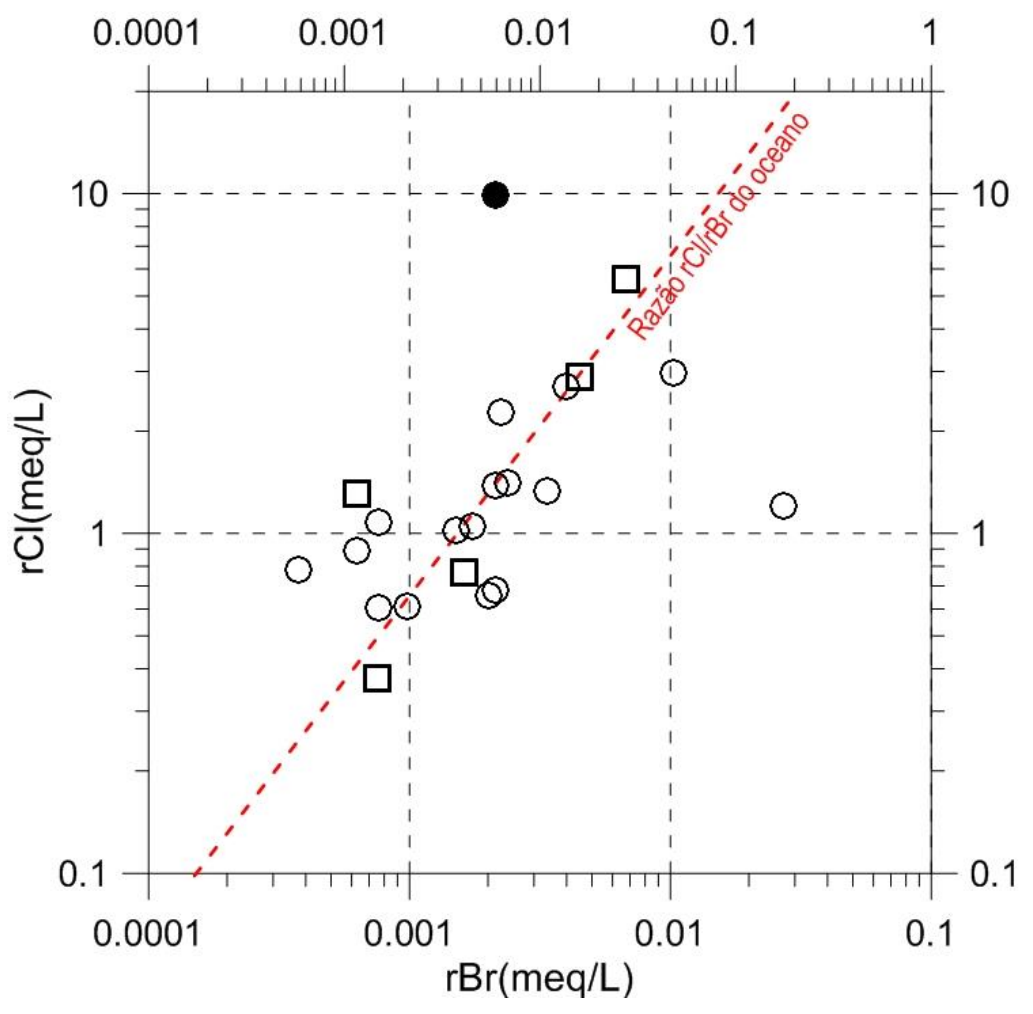

Figura 11 - Razão Iônica rCl/rBr. Quadrados: campanha de 2000; Círculos: campanha de 2010-2012; Círculo negro: Amostra do aquífero profundo (Ponto 9). CUSTODIO \& LLAMAS, 1976

Figure 11 - rCl/rBr Ion ratio. Quadrados: campanha de 2000; Círculos: campanha de 20102012; Círculo negro: Amostra do aquífero profundo (Ponto 9). CUSTODIO \& LLAMAS, 1976 


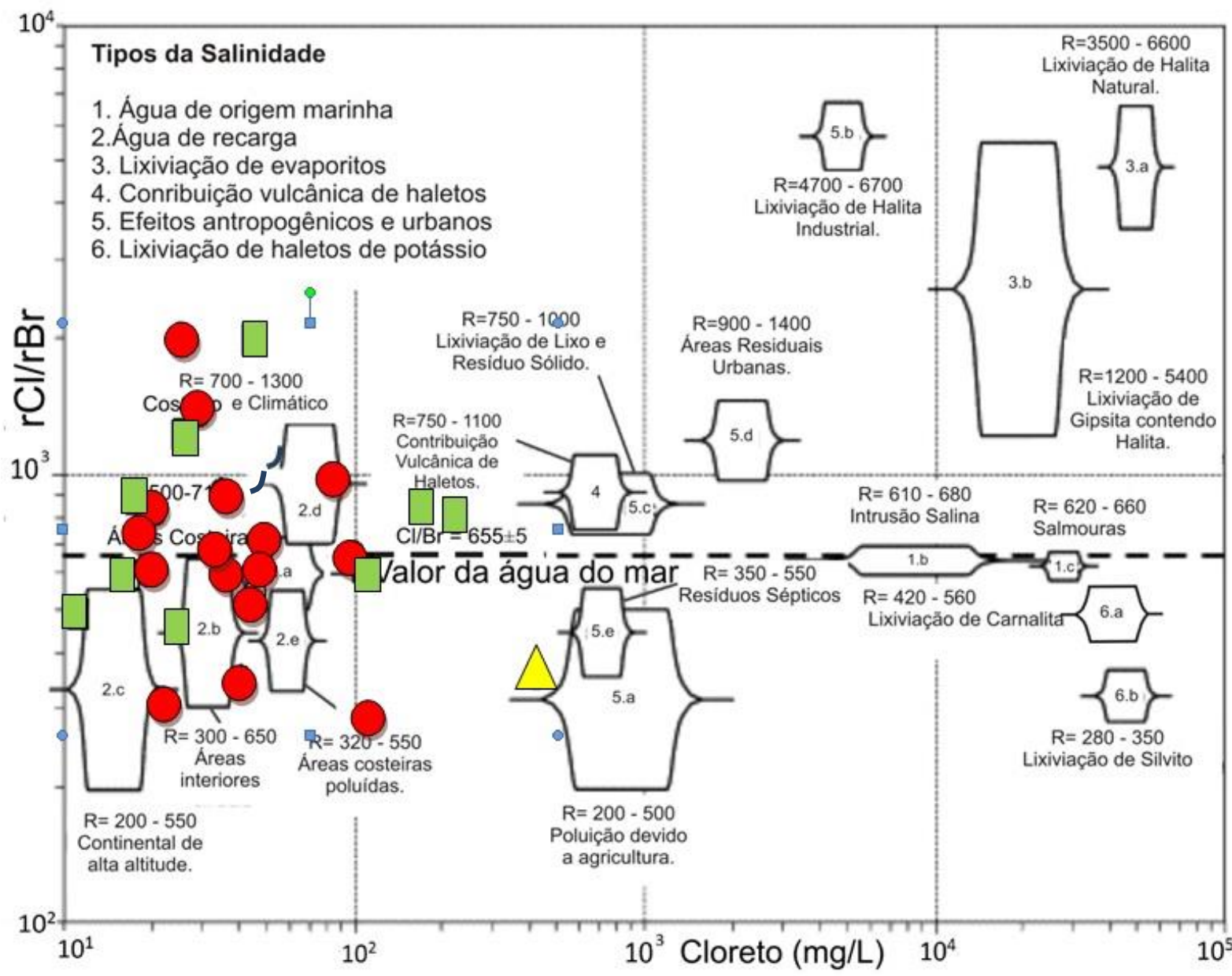

Figura 12 - Gráfico com a razão $\mathrm{Cl} / \mathrm{Br}$ por Cloreto para os seis principais processos de aumento da salinidade (adaptado de Alcalá e Custodio, 2008). Quadrados verdes: campanha de 2000; Círculos vermelhos: campanha de 2010-2012; Triângulo Amarelo: Amostra do aquífero profundo (Ponto 9)

Figure $12-\mathrm{Cl} / \mathrm{Br}$ vs. Chloride ion ratio for the six main processes leading to increasing salinity (adapted from Alcalá and Custodio, 2008). Quadrados verdes: campanha de 2000; Círculos vermelhos: campanha de 2010-2012; Triângulo Amarelo: Amostra do aquífero profundo (Ponto 9)

De maneira geral, as águas dos poços apresentam relações iônicas típicas de águas continentais, com moderada a forte influência marinha, com algumas exceções. A mais notável exceção corresponde ao Ponto 9, que representa o aquífero profundo que ocorre praticamente na linha de costa e que é explotado por alguns habitantes do local. Nessa área de praia, o aquífero superficial é salinizado. A assinatura hidrogeoquímica da água do Ponto 9 aponta, nas várias relações iônicas analisadas, para uma fácies distinta do ponto de vista geoquímico do aquífero profundo, possivelmente uma paleoágua.

\section{CONCLUSÕES}

Através da amostragem sistemática e análises de água subterrânea em poços rasos do aquífero freático de Itaipuaçu em períodos distintos, no ano 2000 e em 2010-2012, foi possível, além de apontar e identificar os principais aspectos hidrogeoquímicos, os efeitos da presença da interface salina e outros processos, avaliar a evolução temporal ao longo do período analisado. Traçou-se um paralelo entre os dois períodos de amostragem, 2000 e 2010-2012, já que as amostras coletadas no período mais antigo (SILVA JR. et al., 2005) e no mais recente (CRISTO \& SILVA JR., 2011; EGER, 2012) estão distribuídas de maneira a permitir esta comparação. Observa-se que o poço ITA 36 possui uma assinatura geoquímica muito semelhante à água do mar, em que pese à distância e profundidade, levando a suposição de que a porção mais profunda do aquífero raso está salinizada pela dispersão/difusão da água marinha moderna.

As águas nos dois períodos estudados apresentaram-se de modo geral aptas para o consumo humano, do ponto de vista dos íons dissolvidos. As razões iônicas, utilizadas neste tra- 
balho, mostraram ser ferramentas que podem ajudar na interpretação do comportamento da migração da cunha salina deste aquífero.

A amostragem e análise realizadas no ano de 2010-2012 e no período anterior não dão indicações de que haja um problema de intrusão marinha no aquífero de Itaipuaçu. Não obstante, o aquífero costeiro de Itaipuaçu apresenta em al- guns pontos indícios de contaminação antrópica. Possivelmente, as camadas de argila e matéria orgânica presentes na extensão da baixada de Itaipuaçu, do canal da Costa para norte da área, funcionam como uma barreira à salinidade, o que evita que o mar mescle suas águas com as do aquífero ali presente.

\section{AGRADECIMENTOS}

À FAPERJ pelo auxílio no desenvolvimento desta pesquisa, projeto HidroqRio (2010-2012). E à FINEP pelo financiamento Projeto Acost-Rio (2000) e pela cessão dos utilizados no curso deste trabalho.

\section{REFERÊNCIAS}

ALCALÁ, F.J.; CUSTODIO, E. Using the Cl/Br Ratio as a Tracer to Identify the Origin of Salinity in Aquifers in Spain and Portugal. Journal of Hydrology v. 359 n. 1 p. 189-207, 2008.

ALMEIDA, G.M. Estudo do Aquífero Costeiro de Maricá - RJ Instrumentação e Investigação do Comportamento da Cunha Salina. Dissertação de Mestrado - Programa de Pós-Graduação em Geologia, UFRJ, 109 p., 2009.

ALMEIDA, G.M.; SILVA JR., G.C Fatores Hidrogeológicos no Estudo da Intrusão Salina em Aquíferos Costeiros da Região Litorânea do Município de Maricá - RJ. Anuário do Instituto de Geociências-UFRJ v. 302 p. 104-117, 2007.

ALVES, M.G. Diagnóstico ambiental da Região Oceânica de Niterói e Distrito de Inoã - Maricá (RJ): uma visão por geoprocessamento e mapeamento geológicogeotécnico. Tese de Doutorado - Programa de PósGraduação em Geologia, UFRJ, 175 p., 2000.

APPELO, C.A.J.; POSTMA, D. Geochemistry, Groundwater and Pollution. $2^{\text {a }}$ Ed. A Balkema. Rotterdam, Brookfield, 728 p., 2005

BARRETO, A.B. DA C. et al. Hidrogeologia do Estado do Rio de Janeiro - Texto explicativo do Mapa de Favorabilidade Hidrogeológica do Estado do Rio de Janeiro. Rio de Janeiro: CPRM, DRM/RJ, 23 p. 2001.

BONILHA, L.E.C.; BORGES, S.F. Contaminação Antrópica de um Aquífero Costeiro e sua Implicação Para o Planejamento Urbano: Estudo de Caso do Aquífero do MariscalCanto Grande (Bombinhas-SC). In: CONGRESSO BRASILEIRO DE ÁGUAS SUBTERRÂNEAS, 12.. Anais... Florianópolis: ABAS, 2002. 1 CD-ROM.

CABRAL, J.J.S.P.; PAIVA, A.L.R. Água subterrânea: Aquíferos Costeiros e Aluviões, Vulnerabilidade e Aproveitamento. Capitulo 4 - Salinização de Aquíferos Costeiros: Investigação e Modelagem. Recife: Ed Universitária da UFPE, 2004.

COSTA, M.T. Levantamento de parâmetros hidrogeológicos para estudo e modelagem numérica da intrusão marinha em aquíferos costeiros da região Litorânea de Itaipuaçu, Município de Maricá, Rio de Janeiro. Trabalho de Conclusão de Curso - UERJ 71 p., 2001.
COSTA, W.D.; SANTOS, M.A.V; COSTA FILHO, W.D. MONTENEGRO, S.M.G.L.; CABRAL, J.J.S.P.; CAVALCANTI, D.J. Monitoramento dos Aquíferos Costeiros da Região do Recife e Adjacências - Pernambuco-Brasil In: Congresso da Associação Brasileira de Estudos do Quaternário, IX Congresso do Quaternário dos Países de Línguas Ibéricas, II. 2003. Anais... Recife: ABEQUA, 2003.1 CDROM.

CIDE - FUNDAÇÃO CENTRO DE INFORMAÇÕES E DADOS DO RIO DE JANEIRO, Território. 2. Ed. Rio de Janeiro: CIDE, 80 p., 1998.

CPRM - Serviço Geológico do Brasil. Geologia do Estado do Rio de Janeiro: Mapa geológico de Maricá / organizado por Luiz Carlos da Silva e Hélio Canejo da Silva Cunha. Brasília: CPRM. 2a edição revista em 2001, 2001.

CRISTO, V.N.; SILVA JR., G.C. Caracterização e Modelo Hidrogeoquímico do Aquífero do Distrito de Itaipuaçu, Maricá - RJ, Brasil. In: V Seminario Hipanoamericano sobre temas de Hidrogeología, 5, 2011. Anais... Salta: ALHSUD, 2011.

CRUZ, A.; SILVA JUNIOR, G.C.; ALMEIDA, G.M. Modelagem Hidrogeoquímica do Aquífero Freático da Restinga de Piratininga, Niterói-RJ. In: CONGRESSO BRASILEIRO DE ÁGUAS SUBTERRÂNEAS, 14, 2006. Anais... Curitiba: ABAS, 2006.1 CD-ROM.

CUSTODIO, E. \& LLAMAS, M.R.: Evolucion geoquimica de las aguas en los acuiferos. Em: Hidrologia subterranea, v1. Barcelona, Ediciones Omega S.A., 1976, p. 1019-1036.

EGER, G.Z.S. Aspectos Hidrodinâmicos, Balanço Hídrico e Simulação de Fluxo no Aquífero Costeiro de Itaipuaçu, Maricá - RJ. Trabalho de Conclusão de Curso. Departamento de Geologia Rio de Janeiro, 84 p., 2012.

ELIS, V.R.; ROCHA, C.M.; KIANG, C.H. Aplicação de ensaios de resistividade na caracterização do Sistema Aquífero Barreiras/Marituba em Maceió - AL. Revista Brasileira de Geofísica v. 22 n. 2 p. 101-113. São Paulo, 2004.

EMBRAPA. Centro Nacional de Pesquisa de Solos (Rio de Janeiro, RJ). Sistema Brasileiro de Classificação de Solos. Brasília: Embrapa Produção da Informação; Rio de Janeiro: Embrapa Solos, 412p., 1999. 
GHABAYEN, S.M.S.; MCKEEB, M.; KEMBLOWSKIONICI, M. Isotopic ratios for identification of salinity sources and missing data in the Gaza aquifer. Journal of Hydrology. v. 318 n. 1 p. 360-373, 2006.

HINRICHSEN, D. Coastal Waters of the World: Trends, Threats, and Strategies. Washington D.C. Island Press, 1998.

ISA, N.M., ARIS A.Z. SULAIMAN, W.N.A.W. Extent and severity of groundwater contamination based on hydrochemistry mechanism of sandy tropical coastal aquifer. Science of the Total Environment. v. 438 n 1 p. 414-425, 2012.

PAIVA, A.L.R.; CABRAL, J.J.S.P.; FARIAS, V.P.; MONTENEGRO, S.M.G.L. Problemas de Salinização nos aquíferos Costeiros da Região Central da Cidade de Recife. In: CONGRESSO DA ASSOCIAÇÃO BRASILEIRA DE ESTUDOS DO QUATERNÁRIO, IX e CONGRESSO DO QUATERNÁRIO DOS PAÍSES DE LÍNGUAS IBÉRICAS, II. 2003. Anais... Recife: ABEQUA, 2003.1 CD-ROM.

PARK, Y., LEE, J.Y., KIM, J.H.; SONG, S.H., National scale evaluation of groundwater chemistry in Korea coastal aquifers: evidences of seawater intrusion. Environmental Earth Science, v. 66, n 1 p. 707-718, 2012.
PERALTA, A.T. Hydrogeological Characterization in the Barra of Maricá, RJ,Brazil. MSc. Thesis Project. Vriije Univ. Amsterdam, 82 p., 2009.

RINA, K., DATTA, P.S., SINGH, C.K.; MUKHERJEE, S., Isotopes and ion chemistry to identify salinization of coastal aquifers of Sabarmati River Basin. Current Science, v. 104, n 1 p. 335-344, 2013.

RINA，K.; SINGH， C.K.; DATTA， P.S.; SINGH， N.; MUKHERJEE, S., Geochemical modelling, ionic ratio and GIS based mapping of groundwater salinity and assessment of governing processes in Northern Gujarat, India. Environmental Earth Science, v. 69, n 1 p. 2377-2391, 2013.

SILVA JR., G.C.; PIZANI T.C. Vulnerability Assessment in Coastal Aquifers Between Niterói and Rio das Ostras, Rio de Janeiro State, Brazil. Revista Latino-Americana de Hidrogeologia, v. 3, n. 1, p. 93-99, 2003.

SILVA JR., G.C. et al. Relatório Final do Projeto ACOSTRIO: Estudo de aquíferos costeiros no leste do Estado do Rio de Janeiro. PADCT/FINEP. 1:1-324, 2005. 